\title{
lonic Mechanisms Underlying the Excitatory Effect of Orexin on Rat Subthalamic Nucleus Neurons
}

OPEN ACCESS

Edited by:

Yosef Yarom,

Hebrew University of Jerusalem,

Israel

Reviewed by:

Jessica R. Barson,

Drexel University College of Medicine,

United States

Paul Geoffrey Overton,

University of Sheffield,

United Kingdom

Constance Hammond,

Institut National de la Santé et de la

Recherche Médicale (INSERM),

France

*Correspondence:

Jian-Jun Wang

jjwang@nju.edu.cn

Jing-Ning Zhu

jnzhu@nju.edu.cn

tThese authors have contributed equally to this work

‡Present address: Qian-Xing Zhuang,

Department of Physiology, School of Medicine, and Co-innovation Center

of Neuroregeneration, Nantong University, Nantong, China

Received: 11 December 2018 Accepted: 08 April 2019

Published: 24 April 2019

Citation:

Li G-Y, Zhuang Q-X, Zhang X-Y, Wang J-J and Zhu J-N (2019) Ionic Mechanisms Underlying the Excitatory Effect of Orexin on Rat Subthalamic Nucleus Neurons. Front. Cell. Neurosci. 13:153. doi: 10.3389/fncel.2019.00153

\author{
Guang-Ying Li ${ }^{\dagger}$, Qian-Xing Zhuang ${ }^{\dagger \neq}$, Xiao-Yang Zhang ${ }^{\dagger}$, Jian-Jun Wang ${ }^{*}$ \\ and Jing-Ning Zhu*
}

\section{State Key Laboratory of Pharmaceutical Biotechnology and Department of Physiology, School of Life Sciences, Nanjing} University, Nanjing, China

Central orexinergic system deficiency results in cataplexy, a motor deficit characterized with a sudden loss of muscle tone, highlighting a direct modulatory role of orexin in motor control. However, the neural mechanisms underlying the regulation of orexin on motor function are still largely unknown. The subthalamic nucleus (STN), the only excitatory structure of the basal ganglia, holds a key position in the basal ganglia circuitry and motor control. Previous study has revealed a wide distribution of orexinergic fibers as well as orexin receptors in the basal ganglia including the STN. Therefore, in the present study, by using whole-cell patch clamp recording and immunostaining techniques, the direct effect of orexin on the STN neurons in brain slices, especially the underlying receptor and ionic mechanisms, were investigated. Our results show that orexin-A elicits an excitatory effect on STN neurons in rats. Tetrodotoxin (TTX) does not block the orexin-induced excitation on STN neurons, suggesting a direct postsynaptic action of the neuropeptide. The orexin-A-induced inward current on STN neurons is mediated by the activation of both OX1 and OX2 receptors. Immunofluorescence result shows that OX1 and OX2 receptors are co-expressed and co-localized in STN neurons. Furthermore, $\mathrm{Na}^{+}-\mathrm{Ca}^{2+}$ exchangers (NCXs) and inward rectifier $\mathrm{K}^{+}$channels co-mediate the excitatory effect of orexin-A on STN neurons. These results demonstrate a dual receptor in conjunction with the downstream ionic mechanisms underlying the excitatory action of orexin on STN neurons, suggesting a potential modulation of the central orexinergic system on basal ganglia circuitry as well as its related motor control and motor diseases.

Keywords: orexin, subthalamic nucleus, motor control, neuronal excitability, ionic mechanisms

\section{INTRODUCTION}

Orexin (also known as hypocretin) is a neuropeptide first identified in 1998 (de Lecea et al., 1998; Sakurai et al., 1998). There are two splice variants of orexin, orexin-A and orexin-B, both of which exert their physiological functions via two types of G-protein coupled receptors, OX1 and OX2 receptors (Tyree et al., 2018). Orexin-A binds to both receptor subtypes with approximately equal affinity, whilst orexin-B shows a 10-fold selectivity for OX2 receptor (Zhang et al., 2013). 
In the central nervous system, orexin receptors produce excitation by postsynaptic depolarization via activation of non-selective cation channels, inhibition of $\mathrm{K}^{+}$channels and activation of $\mathrm{Na}^{+}-\mathrm{Ca}^{2+}$ exchangers (NCXs), as well as presynaptic action through regulation of the release of other neurotransmitters (Kukkonen and Leonard, 2014; Leonard and Kukkonen, 2014). Although originating exclusively from the lateral hypothalamus/perifornical area, the central orexinergic system projects widely throughout almost the whole brain (Broberger et al., 1998; Peyron et al., 1998; Cutler et al., 1999). Accumulating studies have revealed that the central orexinergic system plays a key position in many basic physiological functions, including the sleep-wakefulness cycle, feeding, energy homeostasis and reward processes (Sakurai, 2007; Matsuki and Sakurai, 2008; Zhang et al., 2013; Giardino et al., 2018). Intriguingly, deficit in the orexinergic system in animals and humans results in cataplexy, a motor dysfunction characterized by sudden loss of muscle tone (Chemelli et al., 1999; Sakurai, 2007). The phenotype indicates that orexin may be directly involved in the somatic motor control. However, the knowledge about orexinergic modulation on motor control is still limited.

The basal ganglia is an essential subcortical center responsible for motor initiation and motor learning, within which the subthalamic nucleus (STN) is the sole structure mainly consisting of excitatory glutamatergic projection neurons. Through widespread innervation on other basal ganglia components, STN provides a powerful driving force for the whole basal ganglia circuitry (Plenz and Kital, 1999). In addition, STN is not only a crucial node in the "indirect" fronto-striatalpallidal-subthalamic pathway, but also forms the "hyperdirect" fronto-subthalamic pathway which directly connects the cortex (Nambu et al., 2002; Kravitz et al., 2010; Chu et al., 2015; Zhuang et al., 2018a). Via sending excitatory input to the internal globus pallidus, the STN balances the activity of the "direct" frontostriatal-pallidal pathway and thus contributes to modulate an appropriate initiation and execution of voluntary movement. Lesion of the STNs leads to ballism (Barlas et al., 2001), a syndrome characterized by continuous, violent, involuntary, wild, and flinging movements of the proximal parts of the limbs. Moreover, a series of recent studies have documented that STN also holds a key position in action selection, response vigor, reinforcement learning, as well as cognitive, emotional, and motivational functions (Wagenbreth et al., 2015; Zavala et al., 2015; Dunovan and Verstynen, 2016; Zénon et al., 2016; Fischer et al., 2017).

Notably, orexinergic cell bodies are localized adjacent to the STN, which send a high-density of projections to the nucleus (Peyron et al., 1998; Sakurai et al., 1998), and even orexin mRNAs can be detected in the STN, indicating a modulatory role of orexin on STN neurons. Moreover, in situ hybridization and immunohistochemical studies have illustrated that the OX1/OX2 receptor mRNAs and proteins are expressed in the STN (Trivedi et al., 1998; Hervieu et al., 2001; Cluderay et al., 2002). By using in vivo electrophysiological recordings, the effect of orexin-A and orexin-B on STN neuronal firing rate has been reported recently (Sheng et al., 2018). However, the ionic mechanisms underlying the excitatory effect of orexin on STN neurons remain unknown. Therefore, in the present study, by using whole-cell patch clamp recording and immunostaining techniques, we showed that orexin directly excited STN neurons via postsynaptic OX1 and OX2 receptors, and the two orexin receptor subtypes co-expressed and co-localized on the same STN neurons. Also, a dual ionic mechanism involving both NCXs and inward rectifier $\mathrm{K}^{+}$channels was found to mediate the orexin-induced excitation on STN neurons.

\section{MATERIALS AND METHODS}

\section{Animals}

The experiments were conducted on Sprague-Dawley rats of either sex, housed under controlled conditions with a lighting schedule of $12 \mathrm{~h}$ light and $12 \mathrm{~h}$ darkness at $22 \pm 2{ }^{\circ} \mathrm{C}$. Standard food and water were provided ad libitum. Rats aged about 14-21 days were used for whole-cell patch clamp recordings since the central orexinergic system seems to reach adult-like levels around P21 in rats and change only slightly in the post-weaning development in Eastern gray kangaroos (Steininger et al., 2004; Yamamoto et al., 2006). Rats aged about 8 weeks were used for immunohistochemical study. All animal experiments were approved by the Experimental Animal Care and Use Committee of Nanjing University and were conducted in accordance with the US National Institutes of Health Guide for the Care and Use of Laboratory Animals (NIH Publication 85-23, revised 2011). All efforts were made to minimize the number of animals used and their suffering.

\section{Whole-Cell Patch Clamp Recordings}

Whole-cell patch clamp recordings were performed as previously described (Zhang et al., 2011; Wang et al., 2017; Zhuang et al., 2018a,b; Ji et al., 2019) on STN neurons on brain slices to assess the effect of orexin and the underlying receptor and ionic mechanisms. According to the rat brain atlas of Paxinos and Watson (2014), sagittal slices (300 $\mu \mathrm{m}$ in thickness) containing the STN were cut (Figure 1A) with a vibroslicer (VT 1200S, Leica) at $4^{\circ} \mathrm{C}$. The slices were incubated in artificial cerebrospinal fluid (ACSF, composition in mM: $124 \mathrm{NaCl}$, $2.5 \mathrm{KCl}, 1.25 \mathrm{NaH}_{2} \mathrm{PO}_{4}, 1.3 \mathrm{MgSO}_{4}, 26 \mathrm{NaHCO}_{3}, 2 \mathrm{CaCl}_{2}$ and 10 D-glucose) equilibrated with $95 \% \mathrm{O}_{2}$ and $5 \% \mathrm{CO}_{2}$ at $35^{\circ} \mathrm{C} \pm 0.5^{\circ} \mathrm{C}$ for at least $1 \mathrm{~h}$ and then maintained at room temperature. During recording sessions, the slices were transferred to a submerged chamber and continuously superfused with $95 \% \mathrm{O}_{2}$ and $5 \% \mathrm{CO}_{2}$ oxygenated ACSF at a rate of $2 \mathrm{ml} / \mathrm{min}$ maintained at room temperature.

Whole-cell recordings were performed on STN neurons with borosilicate glass pipettes (3-5 M $\Omega$ ) filled with an internal solution (composition in $\mathrm{mM}$ : $135 \mathrm{~K}$-methylsulfate, $5 \mathrm{KCl}$, $2 \mathrm{MgCl}_{2}, 10 \mathrm{HEPES}, 5$ EGTA, $0.5 \mathrm{CaCl}_{2}, 4 \mathrm{Na}_{2}$-ATP, 0.4 GTPTris, adjusted to $\mathrm{pH} 7.25$ with $1 \mathrm{M} \mathrm{KOH})$. Recordings of STN neurons were carried out in slices that were superfused with ACSF. STN neurons were visualized with an Olympus BX51WI microscope (Olympus, Tokyo, Japan) equipped with infrared differential interference contrast. Patch-clamp recordings were acquired with an Axopatch-700B amplifier (Axon Instruments, Sunnyvale, CA, USA) and the signals were fed into a computer 
A

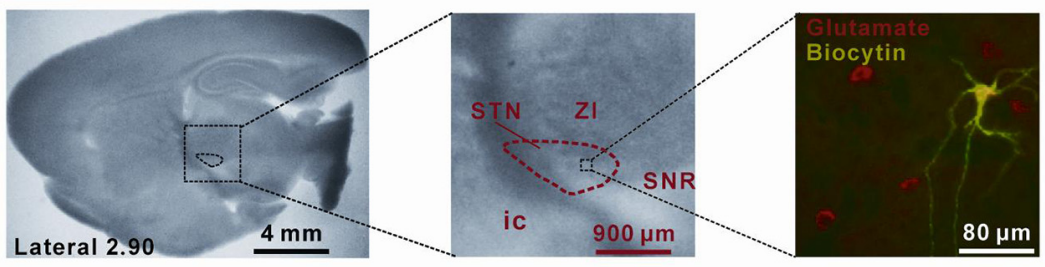

B

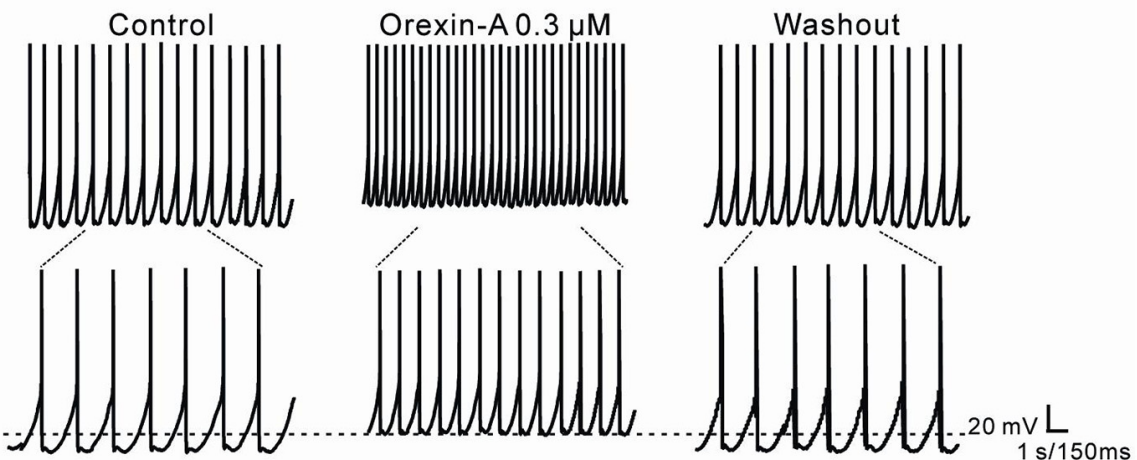

C

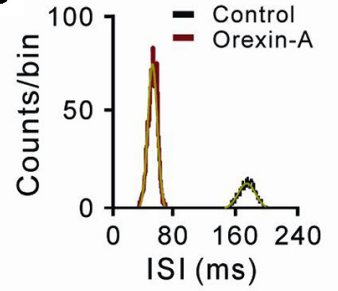

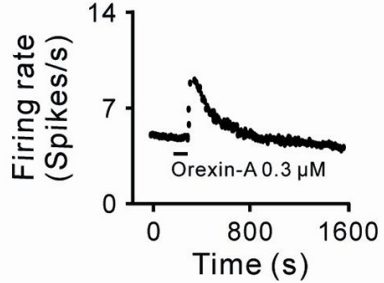

$\mathbf{E}$

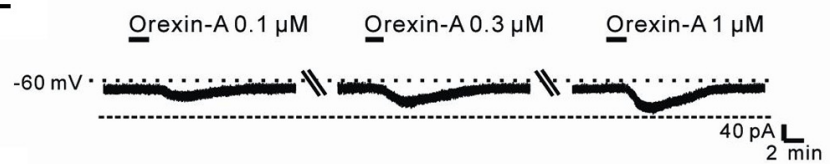

D

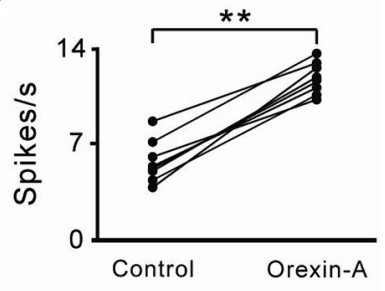

$\mathbf{F}$

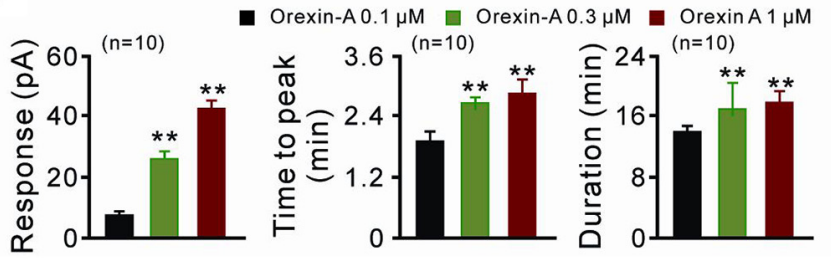

G

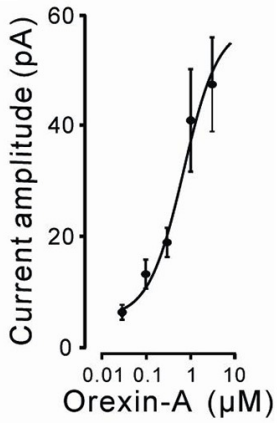

FIGURE 1 | The direct excitatory effect of orexin on the subthalamic nucleus (STN) neurons. (A) Microscope image of a STN which centrally located in a $300 \mu \mathrm{m}$ thick brain sagittal slice (observed with Olympus BX51WI, using a 40x water immersed objective) and a glutamatergic STN neuron labeled with biocytin after patch-clamp recording. (B) Orexin-A (300 nM) excited a STN spontaneous firing neuron in current clamp recording. (C) Orexin changed the distribution of inter-spike intervals (the red curve is Gaussian fit to the data) and increased firing rate of the STN neuron presented in (B). (D) Group data of the effect of orexin-A on firing rate of STN neurons $(n=8)$. (E) Orexin-A concentration-dependently elicited the inward current and increased time to peak and duration of response of the recorded STN neuron. (F) A group of data recorded from 10 STN neurons. (G) Concentration-response curve for orexin-A on STN neurons show mean EC50 value of $29.0 \pm 14.3 \mathrm{nM}(n=8)$. Data are presented as mean $\pm \mathrm{SEM}$; ${ }^{* *} P<0.01$. In this and the following figures, the short horizontal bars above the experimental records indicate the 1 min period of application of orexin-A, and the long horizontal bars indicate the exposure of the slice to tetrodotoxin (TTX), antagonists or blockers of receptors, ion exchangers or channels.

through a Digidata-1440A interface (Axon Instruments) for data capture and analysis (pClamp 10.5, Axon Instruments). Neurons were held at a membrane potential of $-60 \mathrm{mV}$ and characterized by injection of rectangular voltage pulses $(5 \mathrm{mV}$, $50 \mathrm{~ms}$ ) to monitor the whole-cell membrane capacitance, series resistance, and membrane resistance. Neurons were excluded from the study if the series resistance was not stable or exceeded $20 \mathrm{M} \Omega$.

We bathed the slices with orexin-A (0.03-3 $\mu \mathrm{M}$, Tocris, Bristol, UK) to stimulate the recorded neurons. Tetrodotoxin 
(TTX, Alomone Labs, Israel), NBQX (AMPA/kainate receptor antagonist, $20 \mu \mathrm{M}$; Tocris), D-AP5 (NMDA receptor antagonist, $50 \mu \mathrm{M}$; Tocris) and gabazine $\left(\mathrm{GABA}_{\mathrm{A}}\right.$ receptor antagonist, $50 \mu \mathrm{M}$; Tocris) were used to examine the direct postsynaptic effect of orexin-A. SB334867 (10 $\mu \mathrm{M}$, Tocris) and JNJ10397049 (10 $\mu \mathrm{M}$, Tocris), high selective antagonists for OX1 and OX2 receptor respectively, were applied to assess the underlying receptor mechanism. Selective NCX blocker KB-R7943 (50 $\mu \mathrm{M}$, Alomone Labs, Israel), broad spectrum $\mathrm{K}^{+}$ channel blocker $\mathrm{BaCl}_{2}(1 \mathrm{mM})$ and selective inward-rectifier $\mathrm{K}^{+}$channel blocker tertiapin-Q (100 nM, Tocris) were used to explore the underlying ionic mechanism. Moreover, to determine the characteristic of whole cell current induced by orexin-A, in voltage-clamp recordings, current-voltage plots ( $I-V$ curves) were obtained before and during application of orexin-A using a slow ramp command $(d V / d t=-10 \mathrm{mV} / \mathrm{s}$, ranged from -60 to $-120 \mathrm{mV}$ ) to allow for attainment of steady-state conditions.

\section{Immunohistochemistry and Imaging}

The experimental procedures for immunostaining followed our previous work (Li et al., 2017; Wang et al., 2017; Zhuang et al., 2018a,b). Rats were deeply anesthetized with sodium pentobarbital $(65 \mathrm{mg} / \mathrm{kg}$ ) and perfused transcardially with $100 \mathrm{ml}$ normal saline, followed by $250-300 \mathrm{ml} 4 \%$ paraformaldehyde in $0.1 \mathrm{M}$ phosphate buffer. Subsequently, the brain was removed, trimmed and postfixed in the same fixative for $12 \mathrm{~h}$ at $4^{\circ} \mathrm{C}$, and then cryoprotected with $30 \%$ sucrose for $48 \mathrm{~h}$. Frozen coronal sections ( $25 \mu \mathrm{m}$ thick) containing the STN were obtained by using a freezing microtome (CM1860, Leica, Wetzlar, Germany) and mounted on gelatin-coated slides. The slices were rinsed with PBS containing $0.1 \%$ Triton X-100 and then incubated in $10 \%$ normal bovine serum in PBS containing $0.1 \%$ Triton $\mathrm{X}-100$ for $30 \mathrm{~min}$. Sections were incubated overnight at $4^{\circ} \mathrm{C}$ with primary antibody/antibodies, as follows: mouse anti-glutamate (1:1,000; Millipore Sigma, St. Louis, MO, USA; Cat\# MAB5304, RRID:AB_94698), chicken anti-OX1 receptor (1:200; Acris Antibodies GmbH, Germany; Cat\# BP4012, RRID:AB_1005881), rabbit anti-OX2 receptor (1:100; Millipore Sigma; Cat\# AB3094, RRID:AB_91358). After a complete wash in PBS, the sections for single or double immunostaining were incubated in the related secondary antibodies (1:2,000; Life Technologies Carlsbad, CA, USA) conjugated to Alexa Fluor 488 and/or Alexa Fluor 594 (1:2,000, Life Technologies) for $2 \mathrm{~h}$ at room temperature in the dark. The slides were washed and mounted in Fluoromount-G mounting medium (Southern Biotech, Birmingham, AL, USA). Incubations replacing the primary antiserum with control immunoglobulins and/or omitting the primary antiserum were used as negative controls. All micrographs were taken with an inverted laser scanning confocal FluoView FV1000 microscope (Olympus, Tokyo, Japan), equipped with Plan-Apochromat $\times 60 / 1.42 \mathrm{NA}$ oil, $\times 40 / 0.9$ NA dry, $\times 20 / 0.75$ NA dry, and $\times 10 / 0.4$ NA dry objective lenses. Digital images from the microscope were recorded with FV10-ASW 3.1 Viewer Software (Olympus) and image processing was done with Photoshop (Adobe Systems Inc., San Jose, CA, USA).

\section{Statistics}

All data were analyzed with SPSS 17.0 (SPSS, Chicago, IL, USA) and presented as mean \pm SEM Shapiro-Wilk test was used for testing the normality of data. Two-tailed Student's $t$-test was employed for statistical analysis. $P$-values of $<0.05$ were considered to be significant.

\section{RESULTS}

\section{Orexin-A Excites STN Neurons via a Direct Postsynaptic Effect}

In the present study, a total of 70 STN neurons with the input resistance higher than $150 \mathrm{M} \Omega$ were recorded. All the glutamatergic neurons we patched had a diameter $>25 \mu \mathrm{m}$ (Figure 1A) and showed spontaneous firing, which was in agreement with the previous reports (Baufreton et al., 2005; Atherton et al., 2010). In current clamp experiments, brief bath application of orexin-A $(0.3 \mu \mathrm{M}, 1 \mathrm{~min})$ elicited a significant increase in the discharge rate of STN neurons $(8 / 11,72.72 \%)$ from $6.0 \pm 0.5$ spikes/s to $12.0 \pm 0.4$ spikes $/ \mathrm{s}(n=8, P<0.01$; Figures 1B,D). The inter-spike intervals and peri-stimulus time histograms showed that orexin-A largely changed the distribution of inter-spike intervals and increased the firing rate of the STN neurons (Figure 1C). On the other hand, in voltageclamp experiments, $0.1,0.3$, and $1 \mu \mathrm{M}$ orexin-A induced an inward current (from $7.2 \pm 3.7 \mathrm{pA}$ to $24.6 \pm 5.2 \mathrm{pA}$ and $43.5 \pm 4.8 \mathrm{pA}$, respectively, $n=10, P<0.001$, respectively), increased the time to peak (from $1.8 \pm 0.6 \mathrm{~min}$ to $2.5 \pm 0.2 \mathrm{~min}$ and $2.7 \pm 0.8 \mathrm{~min}$, respectively, $n=10, P<0.01$, respectively), and prolonged the duration of response (from $14.8 \pm 0.3 \mathrm{~min}$ to $17.3 \pm 1.0 \mathrm{~min}$ and $17.9 \pm 0.4 \mathrm{~min}$, respectively, $n=10, P<0.01$, respectively) on STN neurons in a dose-dependent manner (Figures 1E,F). Fitting the concentration-response curve from eight STN neurons yielded that the concentration of orexin-A required for half-maximal activation $\left(\mathrm{EC}_{50}\right)$ was $28.3 \pm 11.6 \mathrm{nM}$ (Figure 1G).

Moreover, combined application of TTX $(0.3 \mu \mathrm{M})$, NBQX (20 $\mu \mathrm{M}$, a potent AMPA receptor antagonist), D-AP5 $(50 \mu \mathrm{M}$, a potent NMDA receptor antagonist) and SR95531 (50 $\mu \mathrm{M}$, a $\mathrm{GABA}_{\mathrm{A}}$ receptor antagonist) did not block the orexin-Aelicited inward current on the recorded neurons $(44.3 \pm 2.1 \mathrm{pA}$ vs. $42.3 \pm 1.9 \mathrm{pA}, n=8, P>0.05$; Figures $2 \mathrm{~A}, \mathbf{B}$ ), strongly indicating that orexin excites STN neurons via a direct postsynaptic effect.

\section{Orexin-A Excites STN Neurons by Activation of Both OX1 and OX2 Receptors}

Orexin-A exerts its physiological actions via two G proteincoupled orexin receptors, OX1 and OX2 receptor (Sakurai et al., 1998; Marcus et al., 2001). Therefore, in the present study, we used SB334867 (selective OX1 receptor antagonist) and JNJ10397049 (selective OX2 receptor antagonist) to examine which receptor(s) mediated the orexin-induced excitation on STN neurons (Figure 3). The orexin-A-elicited inward current was partly blocked by separate application of SB334867 (10 $\mu \mathrm{M}$; from $44.5 \pm 2.5 \mathrm{pA}$ to $23.6 \pm 1.4 \mathrm{pA}, n=8, P<0.01$; 
A

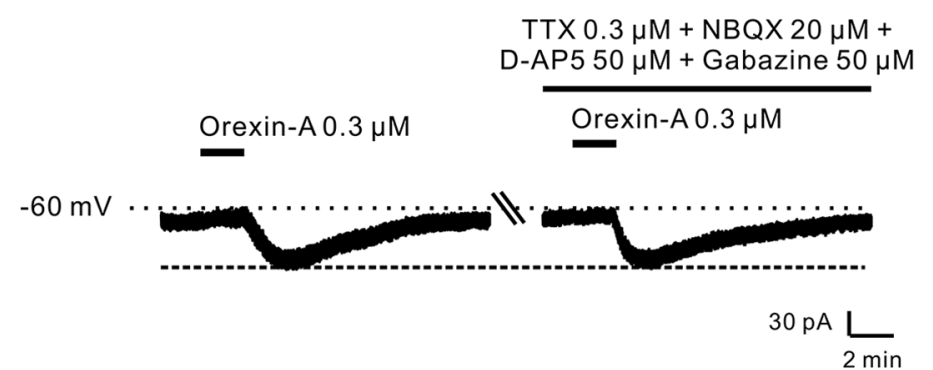

B

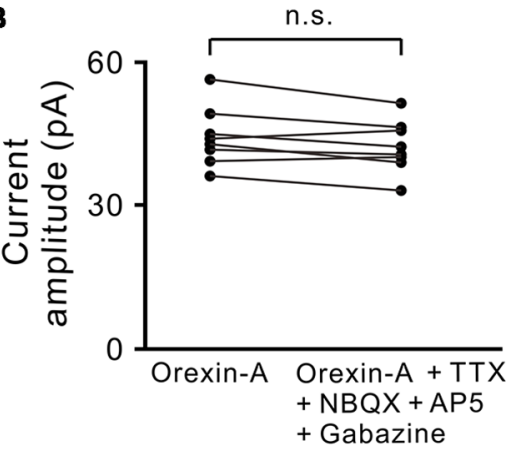

FIGURE 2 | Orexin-A excited the recorded STN neurons with a postsynaptic manner. (A) TTX, NBQX, D-AP5 and gabazine did not block the inward currents induced by orexin-A on a recorded STN neuron. (B) Group data of the recorded STN neurons $(n=8)$. Data are presented as mean \pm SEM; n.s., no statistical difference.

A

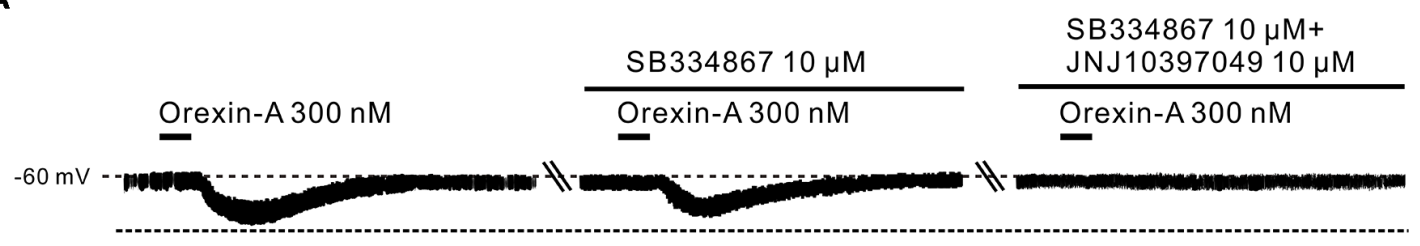

B

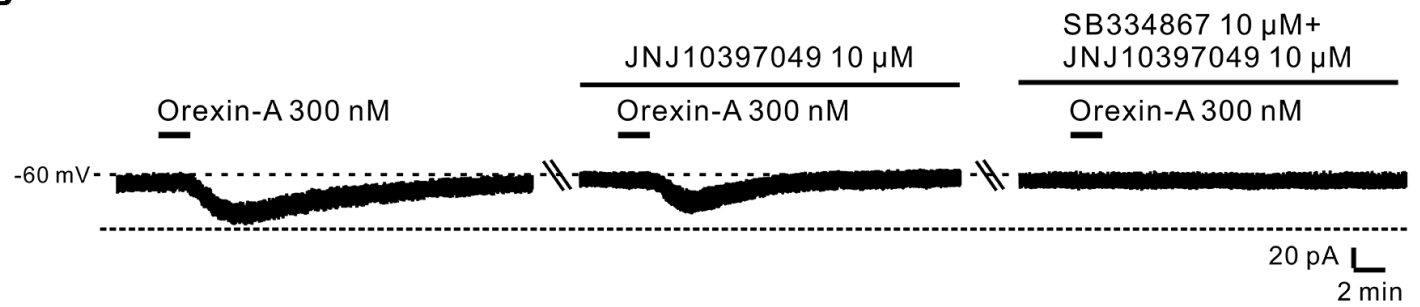

C

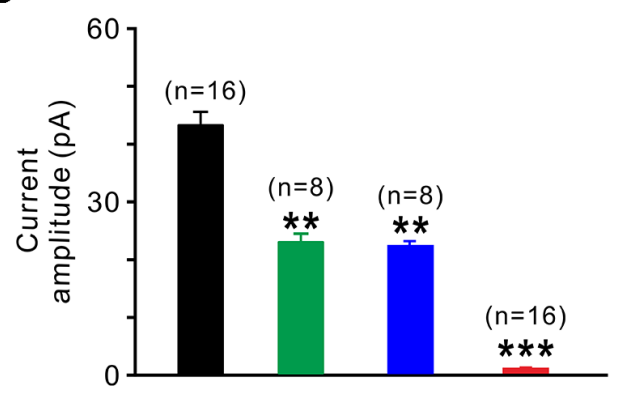

Orexin-A

Orexin-A + SB334867

Orexin-A + JNJ10397049

Orexin-A+SB334867 + JNJ10397049

FIGURE 3 | OX1 and OX2 receptors co-mediate the excitation of orexin on STN neurons. (A) Orexin-A (300 nM) elicited an inward current in a STN neuron, SB334867 (10 $\mu \mathrm{M})$, a selective antagonist for OX1 receptor, partly blocked the current induced by orexin-A and SB334867 combined with JNJ10397049, a selective antagonist for OX2 totally abolished the orexin-A-induced inward current. (B) Orexin-A (300 nM) elicited an inward current in a STN neuron, JNJ10397049 (10 $\mu$ M) partly blocked the current induced by orexin-A and JNJ10397049 combined with SB334867 totally abolished the orexin-A-induced inward current. (C) Group data of the tested STN neurons under orexin-A induced inward current as present in $(\mathbf{A}, n=8)$ and $(\mathbf{B}, n=8)$. Data are presented as mean \pm SEM, ${ }^{* *} P<0.01$, *** $P<0.001$.

Figures 3A,C) or JNJ10397049 $(10 \mu \mathrm{M}$; from $44.6 \pm 2.5 \mathrm{pA}$ to $22.6 \pm 0.5 \mathrm{pA}, n=8, P<0.01$; Figures $3 \mathrm{~B}, \mathrm{C})$. Moreover, combined application of SB334867 and JNJ10397049 nearly totally antagonized the orexin-A-induced excitation from
$44.6 \pm 2.5 \mathrm{pA}$ to $1.2 \pm 0.1 \mathrm{pA}$ on STN neurons $(n=16$, $P<0.001$; Figures $3 \mathrm{~A}-\mathrm{C}$ ). All these results suggest that $\mathrm{OX} 1$ and $\mathrm{OX} 2$ receptors co-mediate the excitatory effect induced by orexin-A on STN neurons. 
Furthermore, the distribution of OX1 and OX2 receptors was mapped in the STN by double immunofluorescence staining. We found that for all the stained sections (five rats and 10 sections for each) both of the orexin receptor subtypes were not only co-expressed in the STN (Figures 4A1-A3,B1-B3) but also co-localized in the same neurons (Figures 4C1-C3), which was consistent with the electrophysiological results mentioned above.

\section{Orexin-A Excites the STN Neurons via Activation of NCXs and Closure of Inward Rectifier $\mathrm{K}^{+}$Channels}

Next, we applied slow-ramp command tests and determined the $I$ - $V$ curves in response to orexin-A to investigate the underlying ionic mechanisms of orexin on STN neurons. We observed three types of the orexin-A-induced changes on the $I-V$ curves from STN neurons $(n=15$; Figures $5 \mathbf{A} 1-\mathbf{A} 3)$. The diversity of the orexin-A-induced changes in $I-V$ relationships implies that more than one ionic mechanism is involved in the orexin-Ainduced excitation on STN neurons. In 8 of 15 neurons, the $I-V$ curves in the absence and presence of orexin-A were apart more at $-130 \mathrm{mV}$ as compared with $-55 \mathrm{mV}$, indicating that ion channels/exchangers with the reversal potential depolarized than $-60 \mathrm{mV}$ may be involved in the orexin-A-induced net current (Figure 5A1). Considering NCXs were reported to be coupled to orexin receptors in many different brain regions and have a more positive reversal potential (Wu et al., 2004; Zhang et al., 2011), we thus speculated that the activation
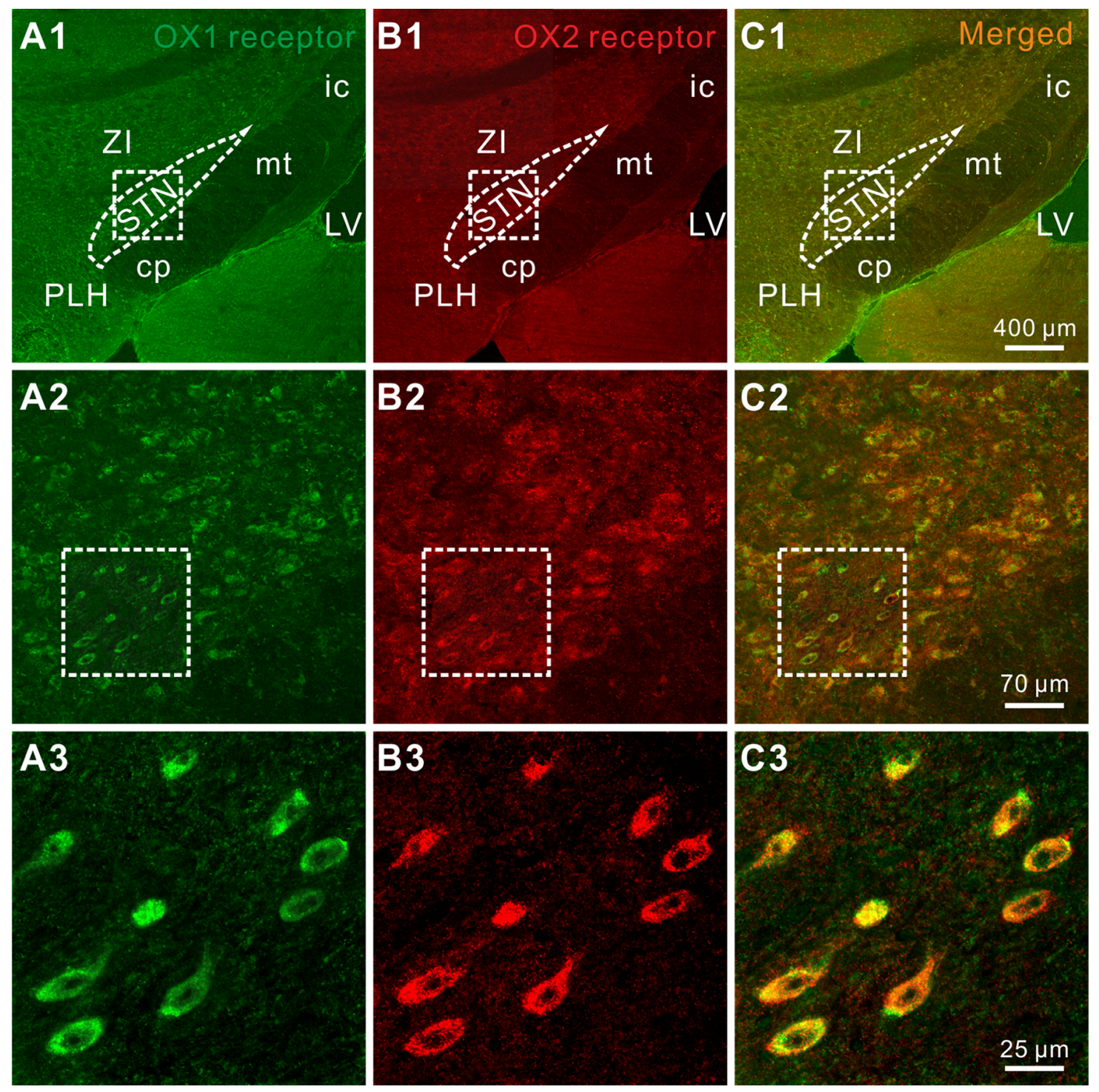

FIGURE 4 | Double-labeled immunofluorescence staining for OX1 (green) and OX2 (red) receptors in rat STN. (A1-A3) OX1 receptor staining. (B1-B3) OX2 receptor staining. (C1-C3) Merged images showing colocalization of OX1 and OX2 receptors in the same STN neurons. STN, subthalamic nucleus; ZI, zona incerta; 3V, 3th ventricle; $4 \mathrm{~V}$, 4th ventricle; $\mathrm{cp}$, cerebral peduncle; ic, internal capsule; mt, mammillothalamic tract; PLH, peduncular part of the lateral hypothalamus. 
A1

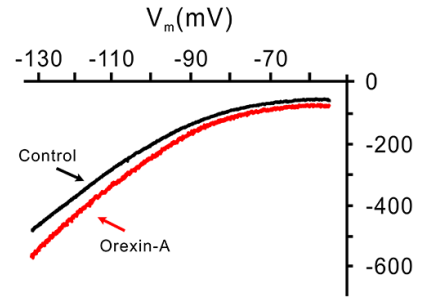

A2

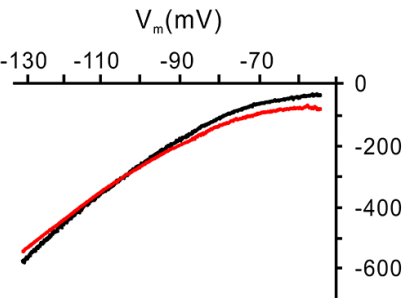

A3

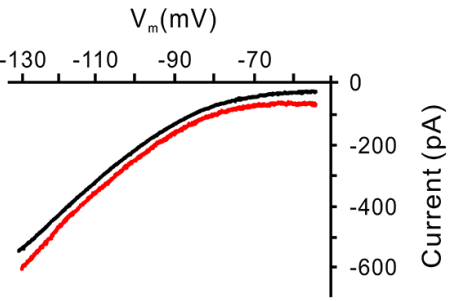

B

$\mathrm{BaCl}_{2} 1 \mathrm{mM}$

$\mathrm{KB}-\mathrm{R} 794350 \mu \mathrm{M}+\mathrm{BaCl}_{2} 1 \mathrm{mM}$

Orexin-A $0.3 \mu \mathrm{M}$

Orexin- $\mathrm{A} 0.3 \mu \mathrm{M}$

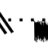

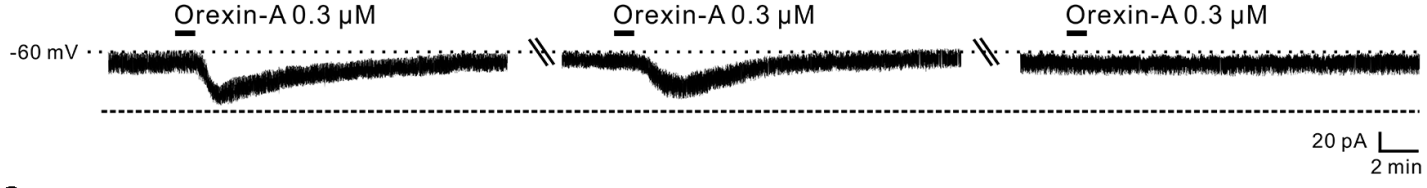

C

KB-R7943 $50 \mu \mathrm{M} \quad \mathrm{KB}-\mathrm{R} 794350 \mu \mathrm{M}+\mathrm{BaCl}_{2} 1 \mathrm{mM}$

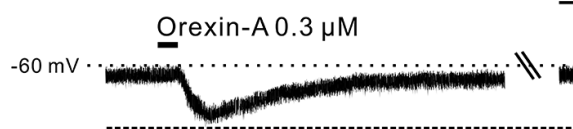

Orexin-A $0.3 \mu \mathrm{M}$

Orexin-A $0.3 \mu \mathrm{M}$

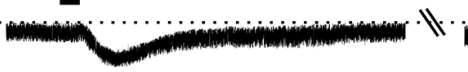

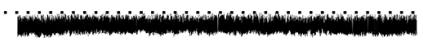

$20 \mathrm{pA} \mathrm{L}$

$\mathbf{D}$

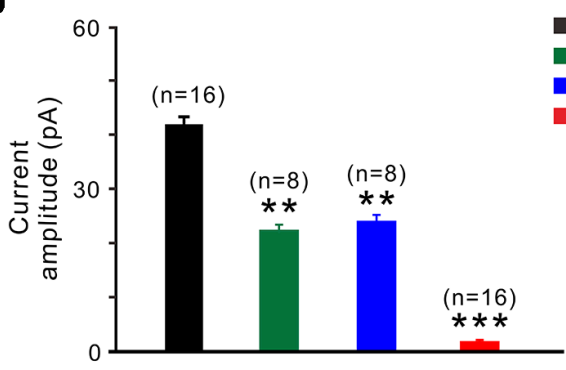

FIGURE 5 | $\mathrm{Na}^{+}-\mathrm{Ca}^{2+}$ exchangers (NCXs) and $\mathrm{K}^{+}$channels co-mediate the excitation of orexin on STN neurons. (A1-A3) $/-V$ relationships of STN neurons in the absence and presence of orexin. In $63.8 \%$ of the neurons tested, the orexin A-induced inward current was larger at the more hyperpolarized potential of $-130 \mathrm{mV}$ than at $-55 \mathrm{mV}$ (A1); in 22.4\% of these neurons tested, the orexin A-induced inward current reversed near the calculated Ek of -105 mV (A2); in 13.8\% neurons, the orexin A-induced inward current first decreased then increase amplitude along with the holding potential hyperpolarization, and was similar in magnitude at -55 and $-130 \mathrm{mV}$ (A3). (B) Orexin-A (300 nM) elicited an inward current in a STN neuron. $\mathrm{BaCl}_{2}$, a broad spectrum blocker of $\mathrm{K}^{+}$channels, partly blocked the effect of orexin-A on STN neurons and combined application of the NCX blocker KB-R7943 totally abolished the orexin-A-induced inward current $(n=8)$. (C) Orexin-A (300 nM) elicited an inward current in a STN neuron. KB-R7943 partly blocked the effect of orexin-A on STN neurons and combined application of the $\mathrm{BaCl}_{2}$ totally abolished the orexin-A-induced inward current $(n=8)$. (D) Group data of the 16 tested STN neurons under orexin-A induced inward current as present in (B,C). Data are presented as mean \pm SEM, ${ }^{* *} P<0.01,{ }^{* * *} P<0.001$.

of NCXs may mediate the orexin-induced change in the $I-V$ relationships. Furthermore, in 5 of 15 recorded STN neurons, the $I-V$ curves in the absence and presence of orexin-A intersected at the $-105 \mathrm{mV}$ (Figure 5A2), which means that the orexin$\mathrm{A}$-induced inward current reverses near the calculated $\mathrm{E}_{\mathrm{k}}$ of $-105 \mathrm{mV}$, thus indicating that $\mathrm{K}^{+}$channels may be involved in the effect of orexin-A on STN neurons. In the remaining two neurons, the orexin-A-elicited change in the $I-V$ curves was similar in amplitudes at -55 and $-130 \mathrm{mV}$ (Figure 5A3), although the amplitude first decreased then increased along with the hyperpolarization.

To further confirm the results of slow-ramp command tests, we applied $\mathrm{Ba}^{2+}$ (a broad spectrum blocker for $\mathrm{K}^{+}$channels) and KB-R7943 (a potent and selective inhibitor for NCXs) to determine whether $\mathrm{K}^{+}$channels and NCXs are involved in the effect of orexin-A on STN neurons. We found a partial inhibition of the orexin-A-induced inward current either by $\mathrm{Ba}^{2+}(1 \mathrm{mM}$; from $41.0 \pm 1.3 \mathrm{pA}$ to $22.2 \pm 0.5 \mathrm{pA}, n=8$, $P<0.01$; Figures 5B,D) or by KB-R7943 application $(50 \mu \mathrm{M}$; from $42.5 \pm 1.7 \mathrm{pA}$ to $24.5 \pm 0.7 \mathrm{pA}, n=8, P<0.01$; Figures 5C,D). Moreover, the orexin-A-induced inward current was totally blocked from $41.8 \pm 1.5 \mathrm{pA}$ to $1.6 \pm 0.2 \mathrm{pA}$ by combined application of $\mathrm{Ba}^{2+}$ and KB-R7943 $(n=16, P<0.001$; Figures 5B-D), suggesting that the closure of $\mathrm{K}^{+}$channels as well as activation of NCXs co-mediated the excitation of orexin-A on STN neurons. 
In order to clarify which kind of $\mathrm{K}^{+}$channels contributes to the excitatory effect of orexin on STN neurons, we further analyzed the characteristics of the orexin-A-induced $\mathrm{K}^{+}$current component. Under a condition of blockage of NCXs by continuously perfusing the slice with KB-R7943, we used slow ramp command tests to obtain the $I-V$ curves in the absence and presence of orexin-A (Figures 6A1,A2). The results showed that the difference current had a reversal potential of $-100 \mathrm{mV}$ that was near the calculated $\mathrm{E}_{\mathrm{k}}$ and exhibited a characterization of strongly outwardly rectifying (Figure 6A2). Since, the closure of $\mathrm{K}^{+}$channels is responsible for depolarization, the result indicates that the $\mathrm{K}^{+}$channels blocked by orexin- $\mathrm{A}$ are the inward rectifier $\mathrm{K}^{+}$channels. As shown in Figures 6B,C, the orexin-A induced inward current on STN neurons was partly blocked by separate application of specific inward rectifier $\mathrm{K}^{+}$ channels antagonist tertiapin-Q (100 nM; from $49.3 \pm 6.8 \mathrm{pA}$ to $27.9 \pm 3.8 \mathrm{pA}, n=10, P<0.01$; Figures $6 \mathrm{~B}, \mathrm{C})$ or KB-R7943 (50 $\mu \mathrm{M}$; from $49.3 \pm 6.8$ to $26.5 \pm 4.6 \mathrm{pA}, n=10$, $P<0.01$; Figures 6B,C), and totally blocked by combined application of KB-R7943 and tertiapin-Q (from $49.3 \pm 6.8$ to $2.5 \pm 0.6 \mathrm{pA}, n=10, P<0.001$; Figures 6B,C). All these results strongly indicate that the excitatory effect of orexin-A on STN neurons is mediated by a dual ionic mechanism including both activation of the NCXs and blockage of the inward rectifier $\mathrm{K}^{+}$channels.

\section{DISCUSSION}

As a driving force for the integrated function of basal ganglia circuitry, the STN plays a key role in the motor initiation and execution. However, little is known about the endogenous factors modulating STN neuronal activity. In the present study, we report that orexin, a hypothalamic neuropeptide, directly excites STN neurons via postsynaptic OX1 and OX2 receptors. And a dual ionic mechanism including activation of the NCXs and closure of the inward rectifier $\mathrm{K}^{+}$channels mediates the excitatory effect of orexin-A on STN neurons.

Previous studies from our laboratory and others have revealed an extensive regulation of orexin on the neuronal activity within the basal ganglia nuclei. It has been documented that there is a selective excitation of orexin-A on the GABAergic neurons in the substantia nigra pars reticulata instead of the dopaminergic neurons in the substantia nigra pars compacta (Korotkova et al., 2002). Moreover, orexin-A directly enhances
A1

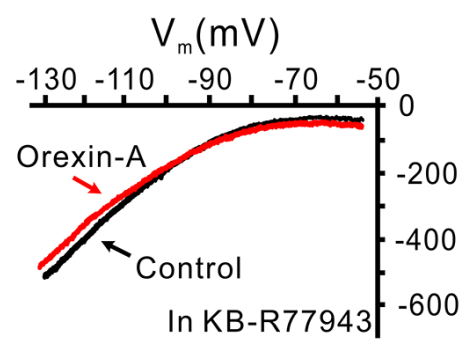

A2

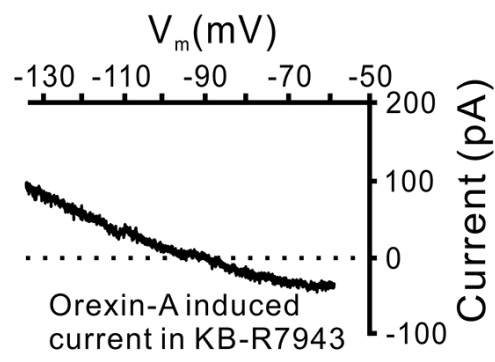

B

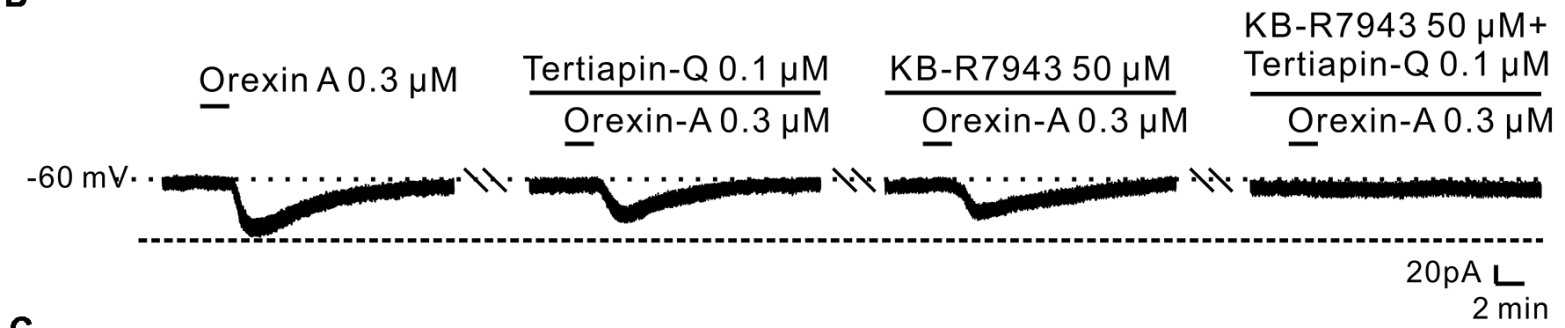

C

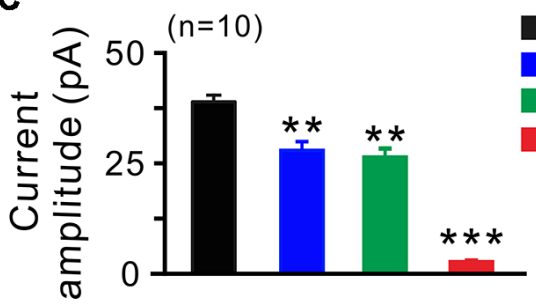

Orexin-A

Orexin-A + Tertiapin-Q

Orexin-A + KB-R7943

Orexin-A + KB-R7943 + Tertiapin-Q

FIGURE 6 | Inward rectifier $\mathrm{K}^{+}$channels and NCXs contribute to the excitatory effect of orexin on STN neurons. (A1,A2) I-V relationship shows an outward rectifier $\mathrm{K}^{+}$current was exposed after KB-R7943 inhibited the activation of the NCX. (B) Orexin-A (300 nM) elicited an inward current in a STN neuron. KB-R7943 partly blocked the effect of orexin-A on STN neurons and combined application of the inward rectifier $\mathrm{K}^{+}$channel antagonist tertiapin- $\mathrm{Q}$ totally abolished the orexin-A-induced inward current. (C) Group data of the 10 tested STN neurons under orexin-A induced inward current as present in (B). Data are presented as mean \pm SEM, ${ }^{* *} P<0.01,{ }^{* * *} P<0.001$ 
the excitability of globus pallidus internus neurons and ventral pallidal GABAergic neurons by direct activation of OX1 and OX2 receptors (Gao et al., 2016; Ji et al., 2019). However, in the striatum, instead of a direct postsynaptic effect, orexin-A potentiates the AMPA-mediated synaptic transmission on the corticostriatal synapses (Shin et al., 2009). In this study, we demonstrate an excitatory action of orexin on neurons in the STN via postsynaptic OX1 and OX2 receptors, which is in accordance with the previous neuropharmacological studies in vivo, previous and present immunohistochemical studies as well as the in situ hybridization on the distribution of orexinergic fibers and receptors (Peyron et al., 1998; Trivedi et al., 1998; Hervieu et al., 2001; Cluderay et al., 2002; Sheng et al., 2018). These results suggest that the central orexinergic system may modulate the major components in the basal ganglia circuitry in parallel and subsequently participate in regulation of motor behaviors, such as biased swing behavior (Sheng et al., 2018).

Several types of ionic channels/exchangers including $\mathrm{K}^{+}$ channels, nonselective cation channels and/or electrogenic NCXs have been reported to be linked to orexin receptors (Lytton, 2007; Kukkonen, 2011; Kukkonen and Leonard, 2014; Ji et al., 2019). In situ hybridization and immunocytochemical studies have revealed the distribution of NCX and inward rectifier $\mathrm{K}^{+}$channel mRNAs in the basal ganglia (Karschin et al., 1994; Murer et al., 1997; Canitano et al., 2002; Jeon et al., 2008). Here, we find that both the NCXs and inward rectifier $\mathrm{K}^{+}$channels are involved in the excitation of STN neurons induced by the activation of orexin receptors. Because of the highly positive reversal potential (Wu et al., 2004), NCXs activation can provide a powerful force for neuronal depolarization. On the other hand, by extruding $\mathrm{Ca}^{2+}$ from the cytoplasm, NCXs prevent $\mathrm{Ca}^{2+}$ overload in the highly excited neurons. Nevertheless, distinct from the NCXs, the activation of inward rectifier $\mathrm{K}^{+}$channels are responsible for the repolarization of membrane action potentials, and their shutoff help to generate a spike (Hille, 2001; Nishida and MacKinnon, 2002). Thus, through activation of NCXs and closure of inward rectifier $\mathrm{K}^{+}$channels, orexin strongly depolarizes and increases the discharge of spontaneous firing STN neurons. We speculate that via the dual ionic mechanism, orexin/central orexinergic system may subsequently bias the excitability of the STN neurons and actively participate in the regulation of STN mediated motor control, action selection, response vigor, reinforcement learning, as well as other cognitive, emotional, and motivational functions (Wagenbreth et al., 2015; Zavala et al., 2015; Dunovan and Verstynen, 2016; Zénon et al., 2016; Fischer et al., 2017).

\section{REFERENCES}

Atherton, J. F., Kitano, K., Baufreton, J., Fan, K., Wokosin, D., Tkatch, T., et al. (2010). Selective participation of somatodendritic HCN channels in inhibitory but not excitatory synaptic integration in neurons of the subthalamic nucleus. J. Neurosci. 30, 16025-16040. doi: 10.1523/JNEUROSCI.389810.2010

Barlas, O., Hanağasi, H. A., Imer, M., Sahin, H. A., Sencer, S., and Emre, M. (2001). Do unilateral ablative lesions of the subthalamic nucleu in parkinsonian patients lead to hemiballism? Mov. Disord. 16, 306-310. doi: 10.1002/mds.1051
The STN holds a key position not only in normal function of the basal ganglia but also in the pathological processes of basal ganglia disorders (Wang et al., 2018). A change in firing rate and/or firing patterns as well as an excess of neuronal synchronization of STN is a well-recognized hallmark in the parkinsonian state, and lesions of the STN have been reported to alleviate the parkinsonian motor symptoms (Bergman et al., 1990; Limousin et al., 1998; Rodriguez et al., 1998). Here, we report a direct excitation of orexin on STN neurons via both OX1 and OX2 receptors and the coupled NCXs and inward rectifier $\mathrm{K}^{+}$channels. Intriguingly, parkinsonian patients show an increasing loss of orexin cells with disease progression and a decrease in orexin level in the cerebrospinal fluid (Fronczek et al., 2007; Thannickal et al., 2007). Therefore, the role of the central orexinergic system in the basal ganglia circuitry including the STN, especially the contribution of endogenous orexin to the basal ganglia motor functions and dysfunctions, needs to be further assessed. The ion channels and exchangers coupled to orexin receptors in the STN might be potential effective targets for the treatment of basal ganglia motor diseases such as Parkinson disease.

\section{ETHICS STATEMENT}

All animal experiments were approved by the Experimental Animal Care and Use Committee of Nanjing University and were conducted in accordance with the US National Institutes of Health Guide for the Care and Use of Laboratory Animals (NIH Publication 85-23, revised 2011). All efforts were made to minimize the number of animals used and their suffering.

\section{AUTHOR CONTRIBUTIONS}

G-YL, Q-XZ and X-YZ performed experiments, analyzed data, and prepared figures and the draft manuscript. J-NZ and J-JW designed research and wrote the article.

\section{FUNDING}

This work was supported by the National Natural Science Foundation of China (grants 31330033, 31471112, 81671107, 31600834, 31771143, and NSFC/RGC Joint Research Scheme 31461163001); the Ministry of Education of China (Fundamental Research Funds for the Central Universities 020814380091); and the Natural Science Foundation of Jiangsu Province, China (grant BK20151384).

Baufreton, J., Atherton, J. F., Surmeier, D. J., and Bevan, M. D. (2005). Enhancement of excitatory synaptic integration by GABAergic inhibition in the subthalamic nucleus. J. Neurosci. 25, 8505-8517. doi: 10.1523/JNEUROSCI. 1163-05.2005

Bergman, H., Wichmann, T., and Delong, M. R. (1990). Reversal of experimental parkinsonism by lesions of the subthalamic nucleus. Science 249, 1436-1438. doi: $10.1126 /$ science. 2402638

Broberger, C., De Lecea, L., Sutcliffe, J. G., and Hökfelt, T. (1998). Hypocretin/orexin- and melanin-concentrating hormone-expressing cells form distinct populations in the rodent lateral hypothalamus: relationship to 
the neuropeptide Y and agouti gene-related protein systems. J. Comp. Neurol. 402, 460-474. doi: 10.1002/(sici)1096-9861(19981228)402:4<460::aid-cne3>3. 3.co; $2-\mathrm{j}$

Canitano, A., Papa, M., Boscia, F., Castaldo, P., Sellitti, S., Taglialatela, M., et al. (2002). Brain distribution of the $\mathrm{Na}^{+} / \mathrm{Ca}^{2+}$ exchanger-encoding genes NCX1, NCX2, and NCX3 and their related proteins in the central nervous system. Ann. N Y Acad. Sci. 976, 394-404. doi: 10.1111/j.1749-6632.2002.tb 04766.x

Chemelli, R. M., Willie, J. T., Sinton, C. M., Elmquist, J. K., Scammell, T., Lee, C., et al. (1999). Narcolepsy in orexin knockout mice: molecular genetics of sleep regulation. Cell 98, 437-451. doi: 10.1016/S0092-8674(00) 81973-X

Chu, H. Y., Atherton, J. F., Wokosin, D., Surmeier, D. J., and Bevan, M. D. (2015). Heterosynaptic regulation of external globus pallidus inputs to the subthalamic nucleus by the motor cortex. Neuron 85, 364-376. doi: 10.1016/j.neuron.2014. 12.022

Cluderay, J. E., Harrison, D. C., and Hervieu, G. J. (2002). Protein distribution of the orexin-2 receptor in the rat central nervous system. Regul. Pept. 104, 131-144. doi: 10.1016/s0167-0115(01)00357-3

Cutler, D. J., Morris, R., Sheridhar, V., Wattam, T. A., Holmes, S., Patel, S., et al. (1999). Differential distribution of orexin-A and orexin-B immunoreactivity in the rat brain and spinal cord. Peptides 20, 1455-1470. doi: 10.1016/s01969781(99)00157-6

de Lecea, L., Kilduff, T. S., Peyron, C., Gao, X., Foye, P. E., Danielson, P. E., et al. (1998). The hypocretins: hypothalamus-specific peptides with neuroexcitatory activity. Proc. Natl. Acad. Sci. U S A 95, 322-327. doi: 10.1073/pnas.95.1.322

Dunovan, K., and Verstynen, T. (2016). Believer-skeptic meets actor-critic: rethinking the role of basal ganglia pathways during decision-making and reinforcement learning. Front. Neurosci. 10:106. doi: 10.3389/fnins.2016. 00106

Fischer, P., Pogosyan, A., Herz, D. M., Cheeran, B., Green, A. L., Fitzgerald, J., et al. (2017). Subthalamic nucleus $\gamma$ activity increases not only during movement but also during movement inhibition. Elife 6:e23947. doi: 10.7554/elife.23947

Fronczek, R., Overeem, S., Lee, S. Y., Hegeman, I. M., van Pelt, J., van Duinen, S. G., et al. (2007). Hypocretin (orexin) loss in Parkinson's disease. Brain 130, 1577-1585. doi: 10.1093/brain/awm090

Gao, H. R., Zhuang, Q. X., Li, B., Li, H. Z., Chen, Z. P., Wang, J. J., et al. (2016). Corticotropin releasing factor excites neurons of posterior hypothalamic nucleus to produce tachycardia in rats. Sci. Rep. 6:20206. doi: 10.1038/srep20206

Giardino, W. J., Eban-Rothschild, A., Christoffel, D. J., Li, S. B., Malenka, R. C., and de Lecea, L. (2018). Parallel circuits from the bed nuclei of stria terminalis to the lateral hypothalamus drive opposing emotional states. Nat. Neurosci. 21, 1084-1095. doi: 10.1038/s41593-018-0198-x

Hervieu, G. J., Cluderay, J. E., Harrison, D. C., Roberts, J. C., and Leslie, R. A. (2001). Gene expression and protein distribution of the orexin-1 receptor in the rat brain and spinal cord. Neuroscience 103, 777-797. doi: 10.1016/s03064522(01)00033-1

Hille, B. (2001). Ionic Channels of Excitable Membranes. 3rd Edn. Sunderland, MA: Sinauer Associates, Inc.

Jeon, D., Chu, K., Jung, K. H., Kim, M., Yoon, B. W., Lee, C. J., et al. (2008). $\mathrm{Na}^{+} / \mathrm{Ca}^{2+}$ exchanger 2 is neuroprotective by exporting $\mathrm{Ca}^{2+}$ during a transient focal cerebral ischemia in the mouse. Cell Calcium 43, 482-491. doi: 10.1016/j.ceca.2007.08.003

Ji, M. J., Zhang, X. Y., Chen, Z., Wang, J. J., and Zhu, J. N. (2019). Orexin prevents depressive-like behavior by promoting stress resilience. Mol. Psychiatry 24, 282-293. doi: 10.1038/s41380-018-0127-0

Karschin, C., Schreibmayer, W., Dascal, N., Lester, H., Davidson, N., and Karschin, A. (1994). Distribution and localization of a G protein-coupled inwardly rectifying $\mathrm{K}^{+}$channel in the rat. FEBS Lett. 348, 139-144. doi: 10.1016/0014-5793(94)00590-7

Korotkova, T. M., Haas, H. L., and Brown, R. E. (2002). Histamine excites GABAergic cells in the rat substantia nigra and ventral tegmental area in vitro. Neurosci. Lett. 320, 133-136. doi: 10.1016/s0304-3940(02)00050-2

Kravitz, A. V., Freeze, B. S., Parker, P. R., Kay, K., Thwin, M. T., Deisseroth, K., et al. (2010). Regulation of parkinsonian motor behaviours by optogenetic control of basal ganglia circuitry. Nature 466, 622-666. doi: 10.1038/ nature09159
Kukkonen, J. P. (2011). A ménage à trois made in heaven: G-protein-coupled receptors, lipids and TRP channels. Cell Calcium 50, 9-26. doi: 10.1016/j.ceca. 2011.04.005

Kukkonen, J. P., and Leonard, C. S. (2014). Orexin/hypocretin receptor signalling cascades. Br. J. Pharmacol. 171, 314-331. doi: 10.1111/bph.12324

Leonard, C. S., and Kukkonen, J. P. (2014). Orexin/hypocretin receptor signalling: a functional perspective. Br. J. Pharmacol. 171, 294-313. doi: 10.1111/bph. 12296

Li, B., Zhuang, Q. X., Gao, H. R., Wang, J. J., and Zhu, J. N. (2017). Medial cerebellar nucleus projects to feeding-related neurons in the ventromedial hypothalamic nucleus in rats. Brain Struct. Funct. 222, 957-971. doi: 10.1007/s00429-016-1257-2

Limousin, P., Krack, P., Pollak, P., Benazzouz, A., Ardouin, C., Hoffmann, D., et al. (1998). Electrical stimulation of the subthalamic nucleus in advanced Parkinson's disease. N. Engl. J. Med. 339, 1105-1111. doi: 10.1056/NEJM199810153391603

Lytton, J. (2007). $\mathrm{Na}^{+} / \mathrm{Ca}^{2+}$ exchangers: three mammalian gene families control $\mathrm{Ca}^{2+}$ transport. Biochem. J. 406, 365-382. doi: 10.1042/bj20070619

Marcus, J. N., Aschkenasi, C. J., Lee, C. E., Chemelli, R. M., Saper, C. B., Yanagisawa, M., et al. (2001). Differential expression of orexin receptors 1 and 2 in the rat brain. J. Comp. Neurol. 435, 6-25. doi: 10.1002/cne.1190

Matsuki, T., and Sakurai, T. (2008). Orexins and orexin receptors: from molecules to integrative physiology. Results Probl. Cell Differ. 46, 27-55. doi: 10.1007/400_2007_047

Murer, G., Adelbrecht, C., Lauritzen, I., Lesage, F., Lazdunski, M., Agid, Y., et al. (1997). An immunocytochemical study on the distribution of two Gprotein-gated inward rectifier potassium channels (GIRK2 and GIRK4) in the adult rat brain. Neuroscience 80, 345-357. doi: 10.1016/s0306-4522(97) 00001-8

Nambu, A., Tokuno, H., and Takada, M. (2002). Functional significance of the cortico-subthalamo-pallidal 'hyperdirect' pathway. Neurosci. Res. 43, 111-117. doi: 10.1016/S0168-0102(02)00027-5

Nishida, M., and MacKinnon, R. (2002). Structural basis of inward rectification: cytoplasmic pore of the $\mathrm{G}$ protein-gated inward rectifier GIRK1 at $1.8 \mathrm{~A}$ resolution. Cell 111, 957-965. doi: 10.1016/S0092-8674(02)01227-8

Paxinos, G., and Watson, C. (2014). The Rat Atlas in Stereotaxic Coordinates. 7th Edn. San Diego, CA: Academic Press.

Peyron, C., Tighe, D. K., van den Pol, A. N., de Lecea, L., Heller, H. C., Sutcliffe, J. G., et al. (1998). Neurons containing hypocretin (orexin) project to multiple neuronal systems. J. Neurosci. 18, 9996-10015. doi: 10.1523/JNEUROSCI.18-23-09996.1998

Plenz, D., and Kital, S. T. (1999). A basal ganglia pacemaker formed by the subthalamic nucleus and external globus pallidus. Nature 400, 677-682. doi: $10.1038 / 23281$

Rodriguez, M. C., Guridi, O. J., Alvarez, L., Mewes, K., Macias, R., Vitek, J., et al. (1998). The subthalamic nucleus and tremor in Parkinson's disease. Mov. Disord. 13, 111-118. doi: 10.1002/mds.870131320

Sakurai, T. (2007). The neural circuit of orexin (hypocretin): maintaining sleep and wakefulness. Nat. Rev. Neurosci. 8, 171-181. doi: 10.1038/nrn2092

Sakurai, T., Amemiya, A., Ishii, M., Matsuzaki, I., Chemelli, R. M., Tanaka, H., et al. (1998). Orexins and orexin receptors: a family of hypothalamic neuropeptides and $\mathrm{G}$ protein-coupled receptors that regulate feeding behavior. Cell 92:696. doi: 10.1016/S0092-8674(00)80949-6

Sheng, Q., Xue, Y., Wang, Y., Chen, A. Q., Liu, C., Liu, Y. H., et al. (2018) The subthalamic neurons are activated by both orexin-A and orexin-B. Neuroscience 369, 97-108. doi: 10.1016/j.neuroscience.2017.11.008

Shin, H. S., Cho, H. S., Sung, K. W., and Yoon, B. J. (2009). Orexin-A increases cell surface expression of AMPA receptors in the striatum. Biochem. Biophys. Res. Commun. 378, 409-413. doi: 10.1016/j.bbrc.2008.11.051

Steininger, T. L., Kilduff, T. S., Behan, M., Benca, R. M., and Landry, C. F. (2004). Comparison of hypocretin/orexin and melanin-concentrating hormone neurons and axonal projections in the embryonic and postnatal rat brain. J. Chem. Neuroanat. 27, 165-181. doi: 10.1016/j.jchemneu.2004.02.007

Thannickal, T. C., Lai, Y. Y., and Siegel, J. M. (2007). Hypocretin (orexin) cell loss in Parkinson's disease. Brain 130, 1586-1595. doi: 10.1093/brain/awm097

Trivedi, P., Yu, H., MacNeil, D. J., Van der Ploeg, L. H., and Guan, X. M. (1998). Distribution of orexin receptor mRNA in the rat brain. FEBS Lett. 438, 71-75. doi: 10.1016/s0014-5793(98)01266-6 
Tyree, S. M., Bomiger, J. C., and de Lecea, L. (2018). Hypocretin as a hub for arousal and motivation. Front. Neurol. 9:413. doi: 10.3389/fneur.2018.00413

Wagenbreth, C., Zaehle, T., Galazky, I., Voges, J., Guitart-Masip, M., Heinze, H. J., et al. (2015). Deep brain stimulation of the subthalamic nucleus modulates reward processing and action selection in Parkinson patients. J. Neurol. 262, 1541-1547. doi: 10.1007/s00415-015-7749-9

Wang, Y., Chen, Z. P., Zhuang, Q. X., Zhang, X. Y., Li, H. Z., Wang, J. J., et al. (2017). Role of corticotropin-releasing factor in cerebellar motor control and ataxia. Curr. Biol. 27, 2661.e5-2669.e5. doi: 10.1016/j.cub.2017.07.035

Wang, Y., Wang, Y., Liu, J., and Wang, X. (2018). Electroacupuncture alleviates motor symptoms and up-regulates vesicular glutamatergic transporter 1 expression in the subthalamic nucleus in a unilateral 6-hydroxydopaminelesioned hemi-parkinsonian rat model. Neurosci. Bull. 34, 476-484. doi: 10.1007/s12264-018-0213-y

Wu, M., Zaborszky, L., Hajszan, T., van den Pol, A. N., and Alreja, M. (2004). Hypocretin/orexin innervation and excitation of identified septohippocampal cholinergic neurons. J. Neurosci. 24, 3527-3536. doi: 10.1523/JNEUROSCI. 5364-03.2004

Yamamoto, Y., McKinley, M. J., Nakazato, M., Yamashita, H., Shirahata, A., and Ueta, Y. (2006). Postnatal development of orexin-A and orexin-B like immunoreactivities in the Eastern grey kangaroo (Macropus giganteus) hypothalamus. Neurosci. Lett. 392, 124-128. doi: 10.1016/j.neulet.2005. 09.014

Zavala, B., Zaghloul, K., and Brown, P. (2015). The subthalamic nucleus, oscillations, and conflict. Mov. Disord. 30, 328-338. doi: 10.1002/mds. 26072

Zénon, A., Duclos, Y., Carron, R., Witjas, T., Baunez, C., Régis, J., et al. (2016). The human subthalamic nucleus encodes the subjective value of reward and the cost of effort during decision-making. Brain 139, 1830-1843. doi: 10.1093/brain/aww075

Zhang, J., Li, B., Yu, L., He, Y. C., Li, H. Z., Zhu, J. N., et al. (2011). A role for orexin in central vestibular motor control. Neuron 69, 793-804. doi: 10.1016/j.neuron. 2011.01.026

Zhang, X. Y., Yu, L., Zhuang, Q. X., Zhu, J. N., and Wang, J. J. (2013). Central functions of the orexinergic system. Neurosci. Bull. 29, 355-365. doi: 10.1007/ s12264-012-1297-4

Zhuang, Q. X., Li, G. Y., Li, B., Zhang, C. Z., Zhang, X. Y., Xi, K. et al. (2018a). Regularizing firing patterns of rat subthalamic neurons ameliorates parkinsonian motor deficits. J. Clin. Invest. 128, 5413-5427. doi: 10.1172/jci99986

Zhuang, Q. X., Xu, H. T., Lu, X. J., Li, B., Yung, W. H., Wang, J. J., et al. (2018b). Histamine excites striatal dopamine D1 and D2 receptor-expressing neurons via postsynaptic $\mathrm{H} 1$ and $\mathrm{H} 2$ receptors. Mol. Neurobiol. 55, 8059-8070. doi: $10.1007 /$ s12035-018-0976-1

Conflict of Interest Statement: The authors declare that the research was conducted in the absence of any commercial or financial relationships that could be construed as a potential conflict of interest.

Copyright (C) 2019 Li, Zhuang, Zhang, Wang and Zhu. This is an open-access article distributed under the terms of the Creative Commons Attribution License (CC BY). The use, distribution or reproduction in other forums is permitted, provided the original author(s) and the copyright owner(s) are credited and that the original publication in this journal is cited, in accordance with accepted academic practice. No use, distribution or reproduction is permitted which does not comply with these terms. 